\title{
UMA ANÁLISE SOBRE O PAPEL FORMADOR DO TRABALHO NA DIALÉTICA DO SENHOR E DO ESCRAVO DE HEGEL
}

\author{
Matheus Pelegrino da Silva ${ }^{1}$
}

\begin{abstract}
RESUMO: O trabalho do escravo, na seção "Dominação e Escravidão" da Fenomenologia do Espírito de Hegel, possui um duplo propósito, tornar o escravo livre de seus desejos e produzir a eliminação do medo da morte. Neste texto apontarei a insuficiência da explicação que Hegel nos dá a respeito de como o trabalho é a causa da negação do medo da morte. A conclusão dessa análise mostrará que a negação do medo da morte não é uma questão menor, mas uma questão fundamental, que tem de ser explicada.
\end{abstract}

Palavras-chave: Dominação; Escravidão; Formação; Hegel; Morte; Trabalho

ABSTRACT: The work of the slave, in the section "Lordship and Bondage" of Hegel's Phenomenology of Spirit, has a double purpose, to make the slave free of his desires and to produce the elimination of the fear of death. In this paper I will point the insufficiency of the explanation that Hegel gives to us about how the work is the cause of the negation of the fear of death. The conclusion of this analysis will show that the negation of the fear of death is not a minor question, but a fundamental one, that have to be explained.

Key-words: Death; Formation; Hegel; Lordship; Bondage; Work

$\mathrm{Na}$ seção "Independência e dependência da consciência-de-si" da Fenomenologia do Espírito Hegel apresenta a primeira forma de relação entre duas consciências. Nessa relação, temos duas consciências que se encontram pela primeira vez, e, em consequência da maneira como cada uma delas se representava e agia, elas entram em conflito, lutam e uma dessas consciências é derrotada e morta ou escravizada. No presente artigo analisaremos um aspecto específico da exposição feita por Hegel dessa relação entre as consciências, a saber, o papel formador do trabalho. Buscaremos, através da análise do texto da Fenomenologia, apontar o alcance e os limites à realização efetiva dessa promessa de formação através do trabalho.

\footnotetext{
${ }^{1}$ Mestrando do Programa de Pós-Graduação em Filosofia da UFRGS, membro do Núcleo de Estudos Hegelianos (NEHGL). Bolsista Capes. Artigo submetido em 18 de outubro de 2009.
} 
Especificamente, indicaremos que Hegel não consegue justificar satisfatoriamente como o trabalho poderia produzir no escravo a perda do medo da morte.

O escravo, ao perder a luta, ficou preso em sua condição de ser no mundo, tornando-se um ser não-livre, um objeto de dominação do senhor, o temor da morte aprisionou o escravo, não fosse a presença deste medo, o escravo aceitaria morrer livre. Tendo isso em vista, “o escravo não é propriamente escravo do senhor, mas da vida; é escravo porque recuou diante da morte, preferiu a escravidão à liberdade na morte"2 ${ }^{\text {. } O}$ escravo escolheu a vida em detrimento da imagem que fazia de si como um ser independente, e, dominado, ele perdeu sua liberdade e se tornou escravo do senhor. O senhor domina o escravo e dele pode exigir tudo, e, então, como o senhor deseja usufruir os objetos, ele se utiliza do escravo para obter tais objetos.

O escravo é obrigado pelo senhor a proporcionar-lhe os objetos de seu desejo, e, assim, o escravo trabalhará para o senhor e seu trabalho consistirá em levar o que existe no mundo ao senhor, para que este satisfaça seus desejos. O escravo não goza dos objetos que obtém com seu trabalho, ele possui contato com a realidade apenas na medida de sua necessidade, não de seu prazer. Ao contrário do seu comportamento em relação ao mundo quando era livre, agora o escravo não consome o objeto que obteve do mundo em razão de seu desejo de dominação, o seu desejo de dominação não conta mais, o que conta é o desejo do senhor. O escravo é forçado pelo senhor, pelo medo de ser morto, a suspender seus desejos e realizar os desejos do senhor. A ação do escravo não é mais guiada por seus desejos, mas sim pelos desejos de um outro, o senhor.

Hegel afirma que o trabalho "é desejo refreado, um desvanecer contido, ou seja, o trabalho forma" ${ }^{\text {”3 }}$ A formação que advém do trabalho é a formação produzida na consciência do escravo, o escravo forma-se através do trabalho. Até estar sob o domínio do senhor, o escravo nunca havia tido a necessidade de refrear seus desejos, ele sempre buscava realizá-los, é somente quando é dominado e sabe que se tentar realizar seus desejos será morto que o escravo realiza a experiência de refrear os seus desejos. Com o

\footnotetext{
2 J. HYPPOLITE, Gênese e estrutura da Fenomenologia do espírito de Hegel. Trad. Andrei José Vaczi, et alii. São Paulo: Discurso editorial, 1999, p. 188.

${ }^{3}$ FE 150, HW 3/153. Grifos do autor. As referências da Fenomenologia do espírito são feitas tendo por base a paginação da edição brasileira, a partir de agora citada com a sigla FE e da edição alemã da Hegel Werke, citada com a sigla HW. HEGEL, Georg Wilhelm Friedrich. Fenomenologia do espírito. Trad. Paulo Meneses. 2. ed. Petrópolis: Vozes, 2003. Hegel Werke. Seitenangabe der Textvorlage Hegel Werke in zwanzig Bänden, Suhrkamp Verlag, 1970. Berlin: Hegel-Institut, Talpa Verlag, 2000. CD-ROM.
} 
trabalho, a consciência do escravo é formada a partir da "retenção do desejo", trabalhando os objetos para seu senhor o escravo é forçado a refrear seus desejos em favor da realização dos desejos do senhor, e, portanto, acaba por libertar-se de seus desejos ao aprender que pode refreá-los. Apesar de parecer muito forte a conclusão de que o escravo liberta-se de seus desejos com o trabalho, ela é perfeitamente adequada ao contexto se tivermos em conta que caso o escravo não contenha seus desejos o senhor não hesitará em fazer valer sua superioridade e matará o escravo. Assim, dada essa expectativa de comportamento por parte do senhor, é razoável afirmar que o escravo, trabalhando, liberta-se de seus desejos, seja do desejo de consumir os objetos, seja, de acordo com a conclusão expressa por Hegel em outro momento do texto, e que trataremos a seguir, o desejo de manter sua vida a todo custo.

A consciência do escravo, através do trabalho, não será "só essa universal dissolução em geral, mas ela se implementa efetivamente no servir. Servindo, suprassume em todos os momentos sua aderência ao ser-aí natural; e trabalhando, o elimina". 5 que se pretende afirmar, nessa passagem, é que quando trabalha a consciência do escravo irá eliminar aquele seu desejo primitivo, aquele desejo que possuía quando se encontrava aderido "ao ser-aí natural", aquele desejo que representava uma "universal dissolução em geral", o desejo que fazia o escravo consumir e destruir o objeto consumido. Ao trabalhar, a consciência do escravo se altera, deixa de ser a consciência que acredita ser capaz de tudo dominar e passa a ser a consciência de um ser que é capaz de dominar não só alguns objetos do mundo, mas inclusive seu próprio desejo de dominação dos objetos. Instaura-se uma nova espécie de dominação, a dominação dos próprios desejos.

Antes do surgimento da relação de dominação, aquele que agora ocupa a posição de escravo realizava seus desejos sempre que estes surgiam, sua relação com as coisas era puramente negativa, o desejo o movia para a destruição das coisas e de sua afirmação como único ser subsistente. Mas essa relação com o mundo não correspondia à realidade, a consciência, então, ficava na esfera da certeza de si, não atingia sua verdade em relação ao mundo. Com o trabalho, a consciência do escravo irá conter seus desejos, não mais terá com as coisas uma relação de pura destruição e auto-afirmação,

\footnotetext{
${ }^{4}$ H. C. de LIMA VAZ, Senhor e Escravo: Uma parábola da filosofia ocidental. Revista Síntese, s. 1., n. 21, 1980, p. 22.

${ }^{5}$ FE 149-50, HW 3/153. [Grifo do autor].
} 
agora o escravo não pode destruir as coisas, ele precisa conservá-las e alterá-las para que, então, elas satisfaçam seu senhor.

A partir dessa nova relação da consciência com a coisa surge a possibilidade de que a consciência finalmente venha a reconhecer-se de modo mais adequado, não apenas como uma certeza de si que se identifica como sendo o simples ato de negar e consumir tudo a sua volta, mas identificar-se como um ser que está no mundo e é capaz de modificar o mundo. Esse conhecimento será exibido à consciência pelos objetos que ela transforma, pelos objetos em que ela põe sua forma individual quando trabalha, e, reconhecendo nos objetos a forma que impôs neles, a consciência reconhece que sua identidade não consiste no simples ato de negar, tampouco consiste na mera submissão a um senhor. A partir da observação de sua forma nos objetos a consciência reconhece que parte de sua natureza é ser um objeto no mundo, é estar no mundo e nele atuar, seja alterando-o, seja negando-o. Nesse sentido é o comentário feito por Bourgeois em relação à função formadora do trabalho: "O sujeito afirma então o objeto - como matéria - ao afirmar-se ele próprio nela - como forma - e para afirmar-se ele próprio em sua realidade verdadeiramente humana, pois a realidade é, primeiro, objetividade". 6

Mas cabe destacar, o conhecimento que a consciência escrava obteve observando os objetos que carregam sua forma subjetiva não constitui ainda a verdade do ser no mundo da consciência escrava. Observando os objetos que estão no mundo e carregam sua forma subjetiva a consciência pode ter a certeza subjetiva de que ela é um ser no mundo, pois aqueles objetos apontam nessa direção e mostram, em sua forma, a impressão que a consciência neles colocou. $\mathrm{O}$ escravo não pode ter acesso à verdade de que ele é um ser no mundo através da observação dos objetos trabalhados, estes objetos não o reconhecem como um ser no mundo, é ele que irá se reconhecer como ser no mundo ao observar as alterações que ele provoca no mundo. O escravo não encontrou um outro ser no mundo que ele considerasse seu semelhante e, ao mesmo tempo, considerasse como um ser no mundo, os objetos não são semelhantes do escravo. O senhor não se considera um ser no mundo, em sua relação com o mundo ele compreende o mundo, tudo o que lhe é exterior, e está no mundo, como algo essencialmente diferente dele, que existe ao lado, e não entre, os seres do mundo. Portanto, o escravo não pode tomá-lo como um semelhante que está no mundo e que

\footnotetext{
${ }^{6}$ B. BOURGEOIS, Hegel - Os atos do espírito. Trad. Paulo Neves. São Leopoldo: Editora UNISINOS, 2004, p. 79.
} 
reconhece o escravo como um ser no mundo. Somente se duas consciências, uma para a outra, se considerarem como seres no mundo, é que elas podem chegar à verdade de que são seres no mundo. O que o escravo obtém, através da observação dos objetos trabalhados por ele é apenas uma certeza, não a verdade, os objetos não afirmam que o escravo é um ser no mundo, é o escravo que afirma de si mesmo esta condição, trata-se de uma certeza subjetiva, o objeto modificado apenas indica uma verdade parcial, a verdade de que o escravo é capaz de alterar o mundo.

Hegel afirma que "a consciência trabalhadora [...] chega assim à intuição do ser independente, como [intuição] de si mesma"7, ou seja, a consciência do escravo intui a si mesma como um objeto independente por meio dos objetos independentes que agora carregam sua forma, a forma que ele impôs aos objetos com seu trabalho. O escravo dáse conta de que ele encontrará sua identidade ao atuar no mundo, interagir com as coisas como uma entre elas e as modificar, e nas modificações reconhecer-se enquanto consciência que não é pura negação do mundo, mas que está no mundo alterando-o e, desta maneira, em parte permanecendo nele por meio dos objetos que transforma.

A formação produzida pelo trabalho não reside apenas na libertação do escravo de seus desejos, ela vai além, é uma etapa da formação da própria consciência-de-si do escravo. Com o trabalho, o escravo toma ciência do fato de que sua existência no mundo não se esvairá com sua morte, pois, na medida em que os objetos agora exibem a forma pessoal que lhes foi imposta pelo escravo, o aspecto subjetivo da consciência sobreviverá à sua morte na forma subjetiva imposta aos objetos do mundo. Quando a consciência se torna independente de seu existir atual, ela nega o medo que antes possuía e que a colocou na condição de dominada por um senhor. Neste sentido, Kojève afirma que "o homem que trabalha reconhece no mundo efetivamente transformado por seu trabalho sua própria obra: ele reconhece a si mesmo; ele vê aí sua própria realidade humana". 8 De modo ainda mais explícito, encontramos a seguinte afirmação de Hyppolite: "A coisidade diante da qual o escravo tremia é eliminada, e o que aparece no elemento da coisidade é o puro ser-para-si da consciência. Logo, o ser-em-si, o ser da

\footnotetext{
${ }^{7}$ FE 150, HW 3/154.

${ }^{8}$ A. KOJÈVE, Introduction à la lecture de Hegel. Paris: Gallimard, 2000, p. 31.
} 
vida, já não está separado do ser-para-si da consciência, mas o trabalho da consciência de si eleva-se à intuição de si mesma no ser". 9

Agora chegamos a um ponto sensível do argumento sobre o papel formador do trabalho, Hegel afirma que através do trabalho o escravo perderá o medo da morte ${ }^{10}$, mas não indica o que levaria a tal perda. Apresentaremos, a seguir, algumas alternativas de solução do problema, e buscaremos apontar como nenhuma das alternativas parece ser plenamente satisfatória.

Segundo a interpretação de Pinkard, com o trabalho o escravo aprenderia que os objetos somente têm valor para o senhor quando lhe são dados por ele, escravo, pois o senhor deseja obter tais objetos de maneira incondicional e sem qualquer esforço de sua parte. Pinkard afirma:

Porque o escravo internalizou o ponto de vista subjetivo do mestre a respeito das coisas como a "verdade", como o ponto de vista objetivo nos termos do qual ele deve julgar seu próprio ponto de vista subjetivo, ele entende que estes objetos contam como algo de valor na medida em que ele, o escravo, trabalha neles. ${ }^{11}$

Surge para o escravo um novo ponto de vista, ele aprende que seu trabalho é valioso ao senhor, que o senhor depende dele para gozar dos objetos que deseja. Agora o escravo sabe que as coisas valem apenas na medida em que são trabalhadas por ele, o escravo aprende que "os objetos naturais do mundo contam como coisas de valor apenas na medida em que ele, o escravo, os integra em um esquema de satisfação de desejo". ${ }^{12}$ Podemos supor, considerando as afirmações de Pinkard, que o escravo perderia o medo da morte pois saberia ou suporia que o senhor, por dar valor aos objetos que o escravo

\footnotetext{
${ }^{9}$ J. HYPPOLITE, Gênese e estrutura da Fenomenologia do espírito de Hegel, op. cit., p. 191.

${ }^{10}$ Inferimos essa afirmação a partir do seguinte trecho: "No entanto, o formar não tem só este significado positivo, segundo o qual a consciência escrava se torna para si um essente como puro ser-para-si. Tem também um significado negativo frente a seu primeiro momento, o medo. Com efeito: no formar da coisa, torna-se objeto para o escravo sua própria negatividade, seu ser-para-si, somente porque ele suprassume a forma essente oposta. Mas esse negativo objetivo é justamente a essência alheia ante a qual ele tinha tremido. Agora, porém, o escravo destrói esse negativo alheio, e se põe, como tal negativo, no elemento do permanecer: e assim se torna, para si mesmo, um para-si-essente." FE 150, HW 3/154. [Grifos do autor].

${ }^{11}$ T. PINKARD, Hegel's Phenomenology: The Sociality of Reason. Cambridge: Cambridge University Press, 1998, p. 61-2. [Grifos do autor].

${ }^{12}$ Idem, ibidem, p. 62. [Grifos do autor].
} 
lhe fornece, não mataria o escravo para não perder aquela condição de gozo em que ele se encontra graças ao escravo. Assim, o escravo perderia o medo da morte pois pensaria que, ao lutar, caso perdesse não seria morto, como seu trabalho tem valor, o escravo acreditaria que com a luta ou ele se libertaria de sua condição de dominação, ou continuaria nesta condição, não haveria risco à sua vida, ele não deveria temer a morte.

Mas o argumento de Pinkard não parece resistir a uma maior análise. Uma primeira crítica que pode ser feita à interpretação por ele oferecida é que Hegel não aponta, em nenhum momento do texto, que o escravo, através do trabalho, dá-se conta de que o senhor valora seu trabalho, assim como não aponta que o escravo descobre que seu trabalho tem valor para o senhor. A segunda crítica que pode ser apontada, e que parece ser mais forte, é que mesmo se aceitarmos que o senhor valora o trabalho do escravo, e que o escravo sabe isto, não se segue que o senhor atribui ao trabalho do escravo um valor absoluto. O senhor, até então, valorava acima de tudo sua autoimagem como ser dominador, e não parece razoável supor que ele abandone esta disposição quando o escravo manifestar seu desejo de libertar-se da dominação. O que parece mais razoável é que o senhor não hesite em matar o escravo que negou a sua condição de dominador ao negar-se a continuar a servir.

Outra interpretação de qual seria o motivo para que o escravo perdesse o medo da morte é apontada a partir da seguinte passagem da Fenomenologia:

Esse meio-termo negativo ou agir formativo é, ao mesmo tempo, a singularidade, ou o puro ser-para-si da consciência, que agora no trabalho se transfere para fora de si no elemento do permanecer; a consciência trabalhadora, portanto, chega assim à intuição do ser independente, como [intuição] de si mesma. ${ }^{13}$

Segundo essa interpretação, o que Hegel estaria afirmando na passagem acima citada é que o escravo aprenderia que ele permanecerá no mundo através de seu trabalho, através da forma subjetiva que ele colocou nos objetos que trabalhou. Tendo aprendido que ele permanecerá por meio dos objetos por ele trabalhado, o escravo deixaria, então, de temer a morte. Seguindo essa linha de interpretação podemos citar

\footnotetext{
${ }^{13}$ FE 150, HW 3/153-4.
} 
Gadamer, pois ele afirma, após mencionar a passagem da Fenomenologia que citamos, o seguinte:

[...] a consciência que trabalha chega a "ver o ser independente como a si mesmo". O significado é claro. Nós temos aqui a autoconsciência da habilidade, que vê a si mesma continuamente e por fim confirmada naquilo que ela "forma" e formou. Através do trabalho, a autoconsciência que é parasi-mesma estabelecida no "elemento da permanência". ${ }^{14}$

Parece ser no mesmo sentido que se desenvolve o argumento de Bourgeois quando ele analisa o papel desempenhado pelo trabalho na formação da consciência. No texto, porém, não é apresentada a razão para que o indivíduo perca o medo da morte, mas podemos apontar alguns indícios de qual seria a posição de Bourgeois. Inicialmente, em sua exposição, Bourgeois cita um grande trecho do $§ 195$ e, a seguir, aponta o papel que o trabalho cumprirá:

[...] promover sua significação intelectual, portanto universalizante, isto é, reconciliadora em sua visão da existência mundana dos homens. O sujeito que trabalha, que se afirma ele próprio através do desvio assim forçado do reconhecimento do objeto, tende por seu sentido, ontologicamente falando, a objetivar-se num objeto que trabalha. ${ }^{15}$

Não fica explicado no texto o que realiza a perda do medo da morte, mas, ao que parece, Bourgeois parece insinuar que, ao "objetivar-se num objeto que trabalha" o sujeito que trabalha perderia o medo da morte. Nessa altura do texto de Bourgeois ocorre a passagem da Fenomenologia para os escritos de Jena, e, então, ele cita um destes escritos: "a ferramenta é 'aquilo em que o [fato de] trabalhar tem sua permanência, é a única [coisa] que resta do trabalhador e do que é trabalhado, e aquilo em que a contingência deles se eterniza". ${ }^{16}$ A respeito do emprego dessa citação, podemos pensar que seriam as ferramentas que garantiriam uma espécie de "imortalidade" do sujeito que trabalha, mas, mesmo que isto seja verdadeiro quanto à

\footnotetext{
${ }^{14}$ H-G. GADAMER, "Hegel's Dialetic of Self-Consciousness". In: J. O'NEILL (Org.). Hegel's Dialectic of Desire and Recognition: Texts and Commentary. New York: State University of New York Press, 1996, p. 164.

${ }^{15}$ B. BOURGEOIS, Hegel - Os atos do espírito, op. cit., p. 79-80.

${ }^{16}$ Id. Ibid., p. 82.
} 
posição de Hegel nos escritos de Jena, não é respondida a questão inicialmente posta, sobre como o sujeito, no contexto da relação entre senhor e escravo, perde o medo da morte. Bourgeois não explica que motivos levariam o leitor a aceitar o recurso aos escritos de Jena para explicar a relação entre senhor e escravo, e, dado que o trabalho surge em contextos muito diversos nos dois textos, a tentativa de explicar o que leva à perda do medo da morte fica frustrada ou, ao menos, pendente de maior justificação.

Aproxima-se da interpretação de Bourgeois a leitura feita por Hyppolite da questão sobre como o trabalho produz a perda do medo da morte. Hyppolite afirma:

[...] nessa operação que parece inessencial [o trabalho] o escravo torna-se capaz de dar a seu ser-para-si a subsistência e a permanência do ser-em-si; o escravo forma-se a si mesmo não somente ao formar as coisas, mas também imprime no ser essa forma que é a da consciência de si, e assim o que encontra em sua obra é ele mesmo. [...] O trabalho do escravo atinge a contemplação do ser independente como sendo de si mesmo. ${ }^{17}$

Assim como Bourgeois, Hyppolite não apresenta, claramente, uma resposta à questão de como ocorre a perda do medo da morte. Ao que parece, tendo em vista os dois trechos acima citados, a interpretação de Hyppolite é no sentido de que o medo da morte é perdido pois, trabalhando, o escravo reconhece a si mesmo nos objetos que trabalhou e colocou a sua forma subjetiva, e, como estes objetos permanecem à sua morte, ele, de certo modo, também permanecerá vivo através da forma subjetiva posta nos objetos.

Por um lado podemos destacar um mérito da exposição de Hyppolite, ressaltar que com o trabalho a consciência escrava assume uma nova postura em relação a si mesma, não se reconhecendo como simples negação de tudo que lhe é externo, mas sim como um ser no mundo, algo que possui uma realidade objetiva. Por outro, deve-se questionar como seria possível, pelo simples fato de uma consciência ter abandonado uma visão subjetiva inteiramente dissociada da realidade externa, que esta consciência possa deixar de temer sua morte. Como ocorreria a passagem do simples reconhecer nos objetos a forma que lhes foi imposta à ideia de que o sujeito irá sobreviver à sua morte biológica? Seguindo esse mesmo enfoque, e objetando tanto à explicação de Hyppolite

\footnotetext{
${ }^{17}$ J. HYPPOLITE, Gênese e estrutura da Fenomenologia do espírito de Hegel, op. cit., p. 191.
} 
como à de Bourgeois, é importante apontar que também resta sem solução a questão de se não seria esperar muito, de uma consciência em um estágio inicial do desenvolvimento de sua subjetividade, que ela fosse capaz de superar seu medo da morte através de pensamentos tão elaborados como a ideia de que ela sobreviverá à sua morte nos objetos que trabalhou.

Como vimos, o trabalho ocupa um papel fundamental no percurso do desenvolvimento da consciência do escravo, eis que cabe a ele transformar a maneira como esta consciência se observa e se comporta no mundo. Nesse contexto, a perda do medo da morte é um elemento indispensável à modificação da relação entre as consciências. Se o escravo não perde o medo da morte, ele não pode voltar a enfrentar seu senhor e buscar sua liberdade. Foi o medo da morte que escravizou a consciência derrotada na luta, e, sem a eliminação deste medo, ela não pode sair de sua condição de escrava. Sem a perda do medo, o progresso no desenvolvimento da consciência é obstaculizado, a consciência que é escrava assim permanece e o mesmo ocorre com a consciência que ocupa a posição de senhor. É tendo atenção a esses elementos que podemos afirmar que a ausência de uma explicação de como o escravo perde o medo da morte representa um grave problema ao argumento de Hegel, eis que ele conceberá as consciências se desenvolvendo através da perda do medo apesar de não ter justificado, satisfatoriamente, como este medo seria superado.

\section{Bibliografia}

BOURGEOIS, Bernard. Hegel - Os atos do espírito. Trad. NEVES, Paulo. São Leopoldo: Editora UNISINOS, 2004.

GADAMER, Hans Georg. "Hegel's Dialetic of Self-Consciousness". In: O’NEILL, John (Org.). Hegel's Dialectic of Desire and Recognition: Texts and Commentary. New York: State University of New York Press, 1996.

HEGEL, Georg Wilhelm Friedrich. Fenomenologia do espírito. Trad. MENESES, Paulo. 2. ed. Petrópolis: Vozes, 2003. 
Hegel Werke. Seitenangabe der Textvorlage Hegel Werke in zwanzig Bänden, Suhrkamp Verlag, 1970. Berlin: Hegel-Institut, Talpa Verlag, 2000. CD-ROM.

HYPPOLITE, Jean. Gênese e estrutura da Fenomenologia do espírito de Hegel. Trad. VACZI, Andrei José et alii. São Paulo: Discurso editorial, 1999.

KOJÈVE, Alexandre. Introduction à la lecture de Hegel. Paris: Gallimard, 2000.

VAZ, Henrique C. de Lima. Senhor e Escravo: Uma parábola da filosofia ocidental. Revista Sintese, s. 1., n. 21, 1980. p. 7-29. 